\title{
Agroecologia no Contexto da Educação do Campo e da Pedagogia da Alternância
}

Agroecology in the context of field education and alternation pedagogy

Leonardo de Miranda Siqueira

Maria Isabel Antunes-Rocha

Luiz Paulo Ribeiro

Resumo: O presente artigo apresenta um recorte de uma pesquisa de doutorado cujo objetivo foi investigar as Representações Sociais dos Educadores dos Centros Familiares de Formação em Alternância Sobre Agroecologia. Em especial, neste artigo, trilhamos o caminho de analisar a compreensão dos educadores do CEFFAS sobre agroecologia. Como metodologia, os dados foram coletados a partir de questionários estruturados. O grupo amostral foi composto por educadores de 18 CEFFAS do Estado do Espírito Santo, onde foram aplicados 110 questionários, tendo retorno de 65 respostas. Os resultados apontaram para uma compreensão de agroecologia ancorada em elementos do contexto dos CEFFAS, assim como elementos que se referem à trajetória dos sujeitos. De toda forma, espera-se que esta pesquisa possa contribuir para aproximação das matrizes: educação do campo, pedagogia da alternância e agroecologia.

Palavras-chave: Campesinato. Agronegócio. Agricultura familiar.

Abstract: This article presents an excerpt from a doctoral research whose objective was to investigate the Social Representations of Educators at the Family Centers of Alternation Training on Agroecology. In particular, in this article, we walk the path of analyzing CEFFAS educators' understanding of agroecology. As a methodology, the data were collected from structured questionnaires. The sample group was composed of educators from 18 CEFFAS, where 110 questionnaires were applied and 65 responses were returned. The results pointed to an understanding of agroecology anchored in elements of the CEFFAS context, as well as elements that refer to the subjects' trajectory. In any case, he hopes that this research can contribute to the approximation of the matrices: field education, alternation pedagogy and agroecology.

Keywords: Peasantry. Agribusiness. Family farming.

\section{Introdução}

Este trabalho empenha-se em apresentar elementos sobre a relação dos educadores dos Centros Familiares de Formação em Alternância (CEFFAS) com agroecologia. Para tanto, traçamos um percurso teórico relacionando a tríade Pedagogia da Alternância-Educação do Campo-Agroecologia, nos esforçamos também em apresentar suas consonâncias, histórias e interrelações enquanto matrizes voltadas aos povos campesinos.

A pedagogia da alternância, que é a orientação pedagógica dos CEFFAS, chegou no Brasil no fim da década de 1960 através da experiência italiana. Para 
Menezes (2013), os CEFFAS brasileiros encontraram na pedagogia de Freire (1987) os pressupostos e os fundamentos epistemológicos que ajudaram na formação de sua identidade, assim, os princípios da pedagogia freiriana foram integrando pouco a pouco na prática sociopedagógica dos CEFFAS. Mesmo sendo surgidas em épocas e contextos diferentes, existem muitos aspectos comuns entre estas duas propostas pedagógicas. A educação contextualizada com a prática da vida, assim como a educação para emancipação dos sujeitos são pressupostos que as unificam, por isso Paulo Freire tem sido utilizado para fundamentar grande parte dos pressupostos pedagógicos da alternância. Ao estudá-las parece que elas tratam de uma mesma proposta pedagógica, talvez esta semelhança esteja em suas raízes humanistas e cristãs de ambas as correntes.

A agroecologia tem suas raízes no movimento da agricultura alternativa datado de meados dos anos 70 no Brasil, sua propagação se deu através de movimentos que contestavam o pacote tecnológico da Revolução Verde ${ }^{1}$, originando posteriormente o agronegócio. A agroecologia então se fortalece como matriz contra hegemônica, crítica dos processos convencionais de produção e do sistema capitalista baseado na modernização e exploração dos trabalhadores, é a negação do agronegócio como um modelo produtivo, que expulsa o agricultor familiar do campo ou que o faz ser submisso. Assim, a defesa desta proposta agroecológica com esta abrangência se alicerça em conhecimentos científicos e saberes populares do campo, que a partir da problematização da realidade, seja ela nos aspectos da produção, dos fatos sociais e das questões políticas, estabelece de forma menos agressiva a relação agricultor-meio ambiente.

Já a educação do campo figura-se como uma matriz que faz a aliança da pedagogia da alternância com agroecologia, foi a partir dos movimentos propulsores da educação do campo que a agroecologia se fortaleceu no contexto

\footnotetext{
${ }^{1}$ Revolução verde foi um movimento mundial que prometia acabar com a fome do mundo através de altas produções, para isso eram utilizadas grandes quantidades de fertilizantes químicos e agrotóxicos, além de um grande aparato de máquinas agrícolas e modificação genética das plantas e animais. Todo este processo causou uma dependência dos agricultores pelo mercado, isto porque todos os insumos da propriedade eram de fontes externas, aumentando o custo de produção (SIQUEIRA, RIBEIRO e ANTUNES-ROCHA, 2020).
} 
dos CEFFAS, isso a partir dos anos 2000. A educação do campo vem se consagrando num movimento nacional que luta por políticas públicas para oferta de uma educação de qualidade aos povos do campo. Um movimento que luta pela desigualdade educacional ofertada aos camponeses, que milita por uma educação de qualidade no campo, que além da estrutura física da escola no campo, também luta por uma proposta educacional própria e apropria aos sujeitos que ali vivem. Para Silva (2010) foi no contexto deste movimento da educação do campo que tem ocorrido, nas últimas décadas, a multiplicação das experiências de formação por alternância em nossa sociedade. O reconhecimento da pedagogia da alternância e seu potencial de transformação das realidades e emancipação dos sujeitos, fez com que sua proposta educativa rompesse o extramuro dos CEFFAS, sobretudo no âmbito do movimento da educação do campo.

A agroecologia já está presente no contexto dos CEFFAS há cerca de 20 anos, de toda forma, diferentes formas de tratá-la e compreendê-la podem ser notadas, isto porque sua formatação contra hegemônica pode provocar tensões nas formas de pensar, sentir e agir dos educadores. Portanto, este trabalho tem o objetivo de analisar as compreensões dos educadores dos CEFFAS sobre agroecologia a partir de uma análise qualitativa dos dados.

\section{Pedagogia da Alternância e Educação do Campo no Contexto da Agroecologia}

Os povos do campo, dadas suas especificidades, se valem do direito a uma educação diferenciada do meio urbano, seu jeito de viver, sua organização comunitária e seus processos de trabalho proporcionam a está população o direito de tal reivindicação. Assim, com a ascensão dos movimentos sociais, principalmente a partir dos anos 80 , período de redemocratização do Brasil, passou a integrar as pautas destes movimentos, cursos que atendessem as especificidades dos povos do campo, principalmente aqueles que levassem as linhas da agroecologia e da educação do campo.

Desde então, diversas experiências de cursos com este enfoque passaram a acontecer pelo Brasil, estes protagonizados pela orientação da 
pedagogia da alternância dos CEFFAS. Entre as instituições proponentes podemos destacar o MST, através do Programa Nacional de Educação na Reforma Agrária (Pronera), as Universidades e outras experiências pelo Brasil.

A partir de 2005, com políticas públicas de apoio a educação do campo, cursos de formação de professores sob a perspectiva da educação do campo e com enfoque em agroecologia passaram a ser oferecidos pelas universidades e instituições públicas. A partir de então, tanto agroecologia quanto a educação do campo, passam por um processo de institucionalização, principalmente pela via pública, inaugurando uma nova era e novas demandas tendo em vista a potencialização de tais movimentos nestes espaços.

A interface pedagogia da alternância, educação do campo e agroecologia se relacionam enquanto práticas pedagógicas e transformações de realidades através da conscientização dos povos do campo. Ambas têm como sujeitos os camponeses e seus territórios enquanto espaços de vida e produção para subsistência, além disso combatem o latifúndio, a monocultura e a dependência de insumos químicos propagados pelo agronegócio. A conexão entre estas três plataformas é essencial para construção de uma proposta educativa libertadora e emancipadora, assim a agroecologia é indissociável da pedagogia da alternância e da educação do campo. De acordo com Ayukawa (2005) a incorporação da agroecologia à educação agrícola, no Brasil, ocorreu a partir da I Conferência "Por uma educação do campo", realizada em 1998, sua primeira menção foi em um texto preparatório para conferência, onde a agroecologia é mencionada como uma reivindicação dos agricultores.

As escolas que utilizam e formularam a pedagogia da alternância são anteriores a educação do campo, mas que as instituições formuladoras da pedagogia da alternância ajudaram a conceber a educação do campo e assumem todos os seus princípios. Desta forma, a pedagogia da alternância pode ser considerada uma pedagogia da educação do campo, isto nos respalda quando referenciarmos a educação do campo, estão inseridos os CEFFAS. A educação com enfoque agroecológico parte de uma visão mais ampla e complexa da realidade, a agroecologia no contexto das escolas do campo pressupõe o entendimento teórico/prático, ou seja, um ensino a partir da práxis. 
O conceito de práxis, de herança marxista, associado ao conceito de prática pedagógica em Freire (1987), e, por conseguinte, à educação na acepção de sentido mais amplo e à ação transformadora é oportuno e atual. Trata-se de atividade humana e social que se manifesta e se realiza na e a partir da realidade, que produz historicamente a unidade entre o homem e o mundo, entre a matéria e o espírito, entre a teoria e a prática, entre o sujeito e o objeto. Teoria e prática são elementos interligados e interdependentes. Ambas são necessárias e se complementam através da práxis. A prática sem a teoria, desprovida da reflexão filosófica, se constitui em atividade cega e repetitiva. A teoria sem o substrato da prática transformadora se constitui num vazio lógico abstrato (PIO, CARVALHO e MENDES, 2015).

A práxis agroecológica apresentou-se, inicialmente, nas escolas de forma a privilegiar o desenvolvimento de técnicas de produção agroecológica com a formação de hortas orgânicas e produção de insumos alternativos. Para tanto, estas escolas têm tentado ir além desta visão técnica, elas têm buscado tratar a agroecologia a partir das dimensões sociais, políticas, culturais e econômicas. A inserção da agroecologia no contexto educacional não foi tarefa fácil, isto porque, a educação agrícola carrega consigo uma marca de comprometimento com as políticas de desenvolvimento adotadas pelo país, assim a introdução da agroecologia nas escolas representa o rompimento deste comprometimento, apresentando uma plataforma marcada pela práxis e pelas suas características contestatórias e de crítica, comprometida com a historicidade e influência dos movimentos sociais do campo (AYUKAWA, 2005).

A educação do campo e a pedagogia da alternância são instrumentalizadas pela agroecologia para enfrentamento do agronegócio. De um lado temos os latifundiários, que proclamam o agronegócio e são subsidiados pelo governo e sua política desenvolvimentista, e do outro os camponeses que têm a agroecologia como matriz organizativa de seu trabalho no campo, e que ao longo dos anos vem sendo reprimida. Assim, a agroecologia pressupõe princípios que proporcionam autonomia aos camponeses, libertando-os da dependência mercadológica ofertada à agricultura por décadas, além do respeito 
ao meio ambiente, o fortalecimento das relações sociais e a geração de renda para as famílias e comunidades (CALDART et al., 2012).

A agroecologia se unifica com a educação do campo através de sua pauta contra hegemônica para educação campesina, que resiste ao avanço das políticas neoliberais e pacotes tecnológicos oriundos da Revolução da Verde. A agroecologia, assim como a educação do campo e a pedagogia da alternância, não tem receitas e fórmulas, mas sim princípios que orientam ambos os movimentos em seus processos de luta. A educação do campo e a pedagogia da alternância, embasadas nos princípios da agroecologia, propõem uma diversificação de atividades profissionais, maior engajamento do jovem no seu meio, a fim de possibilitar a opção de habitar e trabalhar no campo com condições técnicas, intelectuais e ideológicas, de modo a se tornar um protagonista de sua realidade.

Para Fernandes e Molina (2017) a agroecologia foi incorporada na educação do campo como paradigma, isto porque ela é uma ciência que tem suas origens no campesinato e também porque representa hoje um pilar fundamental do confronto necessário à lógica de produção da agricultura capitalista, criadora do agronegócio. Incorporar a agroecologia na pauta da escola do campo é entender que os problemas do campo não são apenas educacionais, mas que existe uma tensão política, social, agrária e econômica gerada pela forma produtiva dos agricultores familiares e do sistema capitalista de produção, neste sentido ambas coexistem e são inseparáveis neste contexto.

De acordo com Sousa (2017), é possível afirmar que, o enfoque agroecológico e a educação do campo, no Brasil, têm a mesma base social de construção inicial, que é a resistência dos agricultores familiares camponeses e seu processo de reorganização a partir dos movimentos sociais.

A defesa de uma nova proposta de desenvolvimento rural e a negação do modelo amparado no agronegócio são partes integrantes dessa aproximação político-filosófica da agroecologia com e a educação do campo. A disputa social e a defesa de mudanças estruturais no campo, como a proposta da reforma agrária massiva no Brasil, também são características comuns dos dois enfoques (SOUSA, 2017, p.7). 
A articulação entre a educação do campo, pedagogia da alternância e a agroecologia pode contribuir para o encontro de uma relação mais harmônica entre o ser humano, a produção e o meio ambiente em todos os aspectos (técnico, econômico, social etc.). Projetos educacionais que vinculem a soberania alimentar, a justiça social, o enfrentamento aos pacotes tecnológicos e $\circ$ fortalecimento da organicidade dos trabalhadores instrumentalizam os estudantes no enfrentamento e nas lutas futuras, isto porque atravessamos um cenário inserto e de mudanças sociais aceleradas. A escola do campo com esta perspectiva assume um papel especial na formação dos sujeitos campesinos, criando um espaço de convivência democrática, onde se respeitam às diferenças e se privilegiam ações coletivas, com objetivos humanos, sociais e técnicos. Adotar uma proposta pedagógica mais interacionista, almejando ser uma instituição que colabore com a comunidade nos processos de fortalecimento da cultura, engajamento social e transformação da realidade social, econômica e psicológica da região, deve estar entre os objetivos do enfoque agroecológico na educação do campo.

Por toda essa discussão, é que a interface entre a agroecologia e a educação do campo adquire extrema importância, uma vez que ambas, enquanto práticas pedagógicas, estão fundamentadas em um modelo alternativo de produzir e socializar conhecimentos. Tanto a educação do campo quanto a Agroecologia pressupõem transformação da realidade, levando em consideração um novo projeto de desenvolvimento do campo que rompa com a lógica da monocultura, do latifúndio e das demais formas de exclusão. Para isso, torna-se necessária a quebra das estruturas econômicas, sociais e políticas de dominação que existem há séculos em nosso país. Assim, entendemos que a conjugação entre a educação do campo e a Agroecologia se apresenta como primordial para a construção de uma educação libertadora, proporcionando aos camponeses e camponesas uma melhor qualidade de vida (RIBEIRO, FERREIRA e NORONHA, 2007, p.262).

É no contexto de reação a ofensiva do agronegócio que a agroecologia e o movimento da educação do campo se encontram e se afirmam, figurando como um instrumento importante na geração de outro projeto de desenvolvimento de campo e de sociedade. Assim, a educação do campo e a agroecologia buscam romper com paradigmas tradicionais, tanto no campo produtivo agrícola, como educacional, solidificando princípios do protagonismo dos camponeses como 
produtores de conhecimento, pesquisadores de suas próprias experiências, que buscam e reivindicam alternativas que contemplem seus modos de produção de vida, de trabalho e cultura (SILVA e MIRANDA, 2015). Os CEFFAS têm oferecido a agroecologia de forma interdisciplinar e não como uma disciplina específica, através de temas geradores ou temas transversais e buscam trabalhar a agroecologia como eixo orientador de suas propostas educativas.

No Brasil, a agroecologia e a educação do campo coexistem e são inseparáveis, portanto é possível traçar pontos de convergência e desafios entre a educação do campo e agroecologia, conforme indicado na figura 1. Um dos pontos de convergência é atuar com intenção de transformar a realidade, através de sua problematização, faz parte da agroecologia assim como da educação do campo, produzir conhecimento científico através dos saberes populares afirmando práticas e metodologias próprias e apropriadas aos camponeses. Portanto, apresentamos na figura 1 uma sistematização dos aspectos desafiadores e convergentes destas duas matrizes tão importantes para 0 campesinato.

Figura 1: Pontos de Convergência e Desafios entre Agroecologia e Educação do Campo/Pedagogia da Alternância

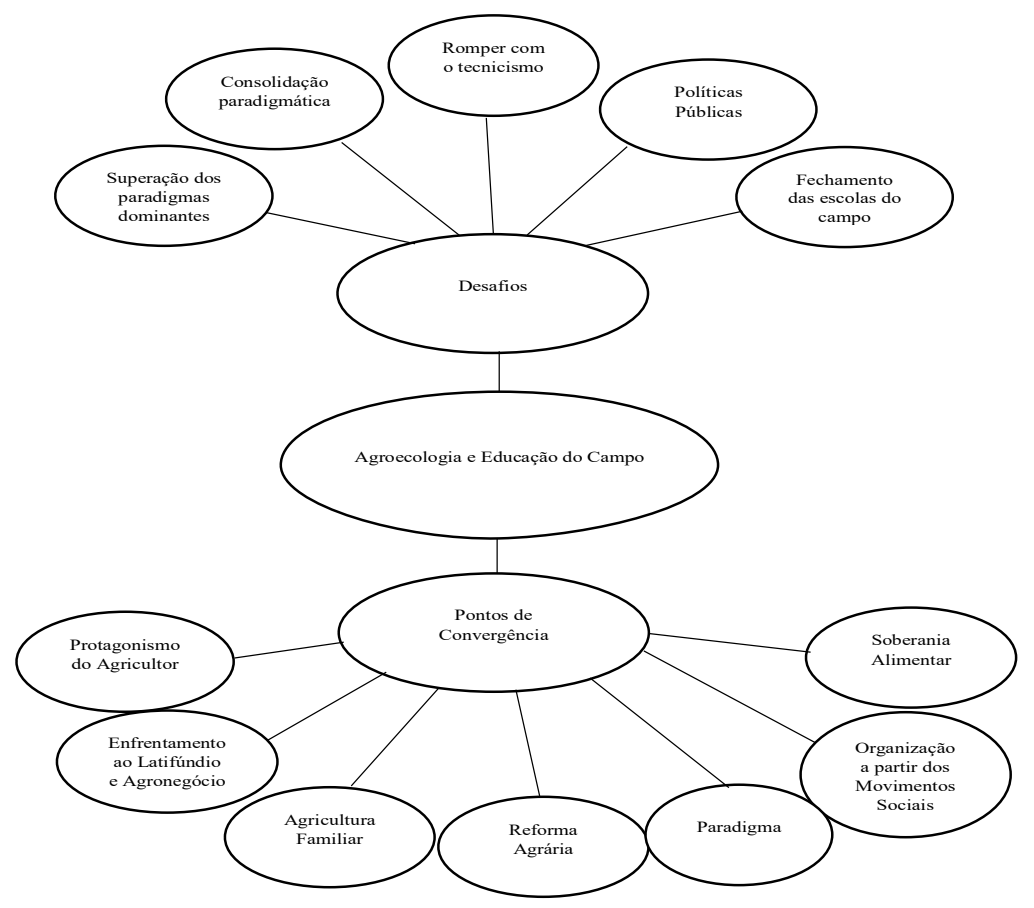

Fonte: Elaborado pelo autor (2020) 
Dentre estas convergências destaca-se a pedagogia da alternância como uma estratégia pedagógica e metodológica utilizada em escolas campesinas, isto porque ela tem elementos pedagógicos que estão em constante diálogo com a realidade do jovem. Projetos educativos pautados pela alternância alimentam uma coerência pedagógica entre teoria e prática, entre o social e o cultural e entre o natural e o estranho. São esses paralelos que levam os estudantes despertar o senso crítico das coisas, de que a sociedade não pode ser aceita da forma como é apresentada, por isso é importante que a vida seja problematizada na escola, para que posteriormente ações transformadoras sejam projetadas. Portanto as matrizes da agroecologia e da educação do campo se convergem e se completam em prol da transformação humanizada do campo.

\section{Percurso Metodológico}

Este trabalho se enquadra como uma pesquisa qualitativa, desta forma para a produção dos dados foram utilizados questionários estruturados que tiveram a função de auxiliar na compreensão destes com relação à agroecologia.

Através dos questionários aplicados foi possível conhecer desde o perfil dos sujeitos participantes da pesquisa até sua inserção socioprofissional, escolaridade, participação sociopolítica, experiência prévia com o objeto (pratica e teórica), dentre outras questões de interesse. Os questionários foram aplicados durante o XXXII Encontro Regional dos Monitores dos Ceffas do norte do estado do Espírito Santo, promovido pela Raceffaes em 2019. As instruções foram dadas ora em grupo, ora individualmente, obedecendo às circunstâncias. Foram distribuídos 110 questionários, com a devolução de 65 questionários respondidos $(n=65)$.

Os sujeitos da pesquisa foram os educadores dos CEFFAS do norte do estado do Espírito Santo, Brasil. Esta escolha se deve em consideração que a região norte do Espírito Santo é composta por oito CEFFAS mantidos pelo MEPES (Movimento de Educação Promocional do Espírito Santo) e dezesseis CEFFAS mantidos pelo poder público municipal, totalizando vinte e quatro CEFFAS. A escolha destes CEFFAS se deu devido aos mesmos receberem assessoria pedagógica da Raceffaes (Regional das Associações dos Centros 
Familiares de Formação em Alternância do Espírito Santo), além do suporte pedagógico na metodologia da alternância, ela contribui na parceria da formação dos educadores, na articulação da escola às instâncias nacionais e internacionais da Alternância.

\section{Apresentação e análise de dados}

Dos 65 educadores pesquisados, 37 são do sexo masculino (57\%) e 28 são do sexo feminino (43\%). Em relação à idade dos respondentes, foram adotados critérios censitários com base no Instituto Brasileiro de Geografia e Estatística - IBGE para a classificação de grupos de faixas etárias. Houve predominância ( $88 \%$ dos respondentes dos questionários) entre a faixa etária de 25 a 49 anos. Verificamos a frequência mais acentuada nas faixas dos 25 aos 29 anos, 30 a 34 anos e 35 aos 39 anos, assim como uma frequência menos acentuada nas faixas dos 20 a 24 anos, 50 aos 54 anos e 55 aos 59 anos. Notase que temos um grupo de educadores adultos jovens, isso mostra que as equipes têm se renovado.

Como ferramenta para alcançarmos nosso objetivo, solicitamos aos educadores que relacionassem cinco palavras que eles associam à agroecologia. Tivemos um total de 325 evocações de palavras, entre as quais relacionamos 52 palavras que se repetiram duas ou mais vezes e 60 palavras que foram evocadas de forma aleatória, sem repetição. Assim, as 52 palavras que tiveram evocações repetidas (conforme tabela 1) somaram 265 evocações, uma média 5 evocações por palavra.

Tabela 1: Relação das palavras evocadas pelos educadores respondentes associadas à agroecologia (evocações e porcentagem, $n=325$ )

\begin{tabular}{|c|c|c|}
\hline Palavra & Evocações & Porcentagem \\
\hline Vida & 35 & $11 \%$ \\
\hline Sustentabilidade & 23 & $7 \%$ \\
\hline Saúde & 19 & $6 \%$ \\
\hline Respeito & 15 & $5 \%$ \\
\hline Equilíbrio & 10 & $3 \%$ \\
\hline Natureza & 7 & $2 \%$ \\
\hline Alimentação & 6 & $2 \%$ \\
\hline
\end{tabular}




\begin{tabular}{|c|c|c|}
\hline Autonomia & 6 & $2 \%$ \\
\hline Cultura & 6 & $2 \%$ \\
\hline Diversidade & 6 & $2 \%$ \\
\hline Integração & 6 & $2 \%$ \\
\hline Amor & 5 & $2 \%$ \\
\hline Cuidado & 5 & $2 \%$ \\
\hline Preservação & 5 & $2 \%$ \\
\hline Soberania & 5 & $2 \%$ \\
\hline Solidariedade & 5 & $2 \%$ \\
\hline Técnica & 5 & $2 \%$ \\
\hline Biodiversidade & 4 & $1 \%$ \\
\hline Ciência & 4 & $1 \%$ \\
\hline Conhecimento & 4 & $1 \%$ \\
\hline Desenvolvimento & 4 & $1 \%$ \\
\hline Meio Ambiente & 4 & $1 \%$ \\
\hline Qualidade & 4 & $1 \%$ \\
\hline Sabedoria & 4 & $1 \%$ \\
\hline Agricultor & 3 & $1 \%$ \\
\hline Ambiente & 3 & $1 \%$ \\
\hline Bem-Estar & 3 & $1 \%$ \\
\hline Consciência & 4 & $1 \%$ \\
\hline Ecologia & 3 & $1 \%$ \\
\hline Humanização & 3 & $1 \%$ \\
\hline Igualdade & 3 & $1 \%$ \\
\hline Justiça & 3 & $1 \%$ \\
\hline Liberdade & 3 & $1 \%$ \\
\hline Luta & 3 & $1 \%$ \\
\hline Movimento & 3 & $1 \%$ \\
\hline Orgânico & 3 & $1 \%$ \\
\hline Produção & 3 & $1 \%$ \\
\hline Coletivo & 2 & $1 \%$ \\
\hline Educação & 2 & $1 \%$ \\
\hline Estudo & 2 & $1 \%$ \\
\hline Organização & 2 & $1 \%$ \\
\hline Persistência & 2 & $1 \%$ \\
\hline Popular & 2 & $1 \%$ \\
\hline Prática & 2 & $1 \%$ \\
\hline Relações & 2 & $1 \%$ \\
\hline Renovação & 2 & $1 \%$ \\
\hline Resistencia & 2 & $1 \%$ \\
\hline Responsabilidade & 2 & $1 \%$ \\
\hline
\end{tabular}




\begin{tabular}{|c|c|c|}
\hline Sementes & 2 & $1 \%$ \\
\hline Sobrevivência & 2 & $1 \%$ \\
\hline Terra & 2 & $1 \%$ \\
\hline Palavras aleatórias & 60 & $18 \%$ \\
\hline Total & $\mathbf{3 2 5}$ & $\mathbf{1 0 0 \%}$ \\
\hline
\end{tabular}

Fonte: Elaborado pelo autor a partir de dados da pesquisa (2020)

Conforme solicitado na questão, as 5 palavras mais evocadas pelos educadores foram, respectivamente: "Vida" com 35 evocações, "Sustentabilidade" com 23 evocações, "Saúde" com 19 evocações, "Respeito" com 15 evocações e "Equilíbrio" com 10 evocações. Neste sentido, a compreensão de agroecologia é construída por meio de um processo psicossocial marcado por valores, ideologias, conceitos e práticas provenientes da história de vida dos educadores e de sua relação no contexto dos CEFFAS, isto compreende sua vivência no CEFFA e fora dele, por isso estas palavras representam elementos importantes na relação entre sujeito (educador) e objeto (agroecologia).

As cinco palavras com maior número de evocações indicam que os educadores ao relacionarem agroecologia estão ancorados numa perspectiva de vida. Ao pensarem na agroecologia, os sujeitos priorizam os aspectos da vida, em detrimento aos aspectos técnicos que estariam relacionados a agricultura em si. Ao evocarem "vida", "sustentabilidade", "saúde", "respeito" e "equilíbrio", evidencia-se o propósito da agroecologia baseada no respeito a todas as formas de vida e também em uma vida com princípios éticos, sociais, políticos e ambientais, assim a agroecologia é colocada como um modo de vida sustentada por pilares de respeito e equilíbrio. A palavra "vida" foi evocada por $54 \%$ dos educadores respondentes, por isso nossa amostra, em sua maioria, associa a agroecologia como uma forma de viver e respeito aos seres vivos, e não apenas como uma forma de trabalhar na terra, sendo esta uma consequência da agroecologia e não o pilar central.

A agroecologia vincula-se com muitas questões práticas, por isso diversas foram as práticas delineadas pelos educadores vinculadas com a agroecologia, estas permearam desde as práticas de cunho técnico até as práticas de cunho pedagógico. Foi possível perceber que a agroecologia é ao mesmo tempo 
composta por elementos práticos, de fácil mensuração, e de elementos reflexivos que alguns educadores têm certa dificuldade de mensuração. A prática agroecológica é importante, mas a prática da agroecologia deve ser refletida e pedagogizada, não basta plantar sem veneno, é preciso fazer reflexões e intervenções de formação da classe trabalhadora, militar e fortalecer os grupos organizados são algumas ações que podem contribuir na pedagogização da agroecologia. Apresentamos na tabela 2 algumas citações dos educadores para definir suas práticas vinculadas a agroecologia, ao mesmo tempo as dividimos em práticas de cunho técnico, voltadas a produção e as práticas reflexivas de cunho pedagógico.

Tabela 2: Práticas relacionadas a agroecologia desenvolvidas pelos educadores respondestes do questionário

\begin{tabular}{|c|c|}
\hline Técnico & Pedagógico \\
\hline $\begin{array}{l}\text { Uso de plantio orgânico } \\
\text { Plantio sem agrotóxico }\end{array}$ & $\begin{array}{c}\text { Cursinhos } \\
\text { Experiências agroecológicas } \\
\text { Defesa e preservação de sementes crioulas } \\
\text { Defesa das organizações sociais do campo } \\
\text { Estudos/pesquisas em agroecologia }\end{array}$ \\
\hline $\begin{array}{c}\text { Caldas } \\
\text { Adubação orgânica } \\
\text { Compostagem } \\
\text { Manejo do Solo }\end{array}$ & $\begin{array}{l}\text { A pedagogia da alternância como um projeto de } \\
\text { educação transformadora }\end{array}$ \\
\hline $\begin{array}{l}\text { Produção de alimentos } \\
\text { Uso de produtos naturais } \\
\text { Produção de sementes }\end{array}$ & Práticas de estudo \\
\hline $\begin{array}{c}\text { Homeopatia } \\
\text { Prática agrícola } \\
\text { Preservação e recuperação da natureza }\end{array}$ & $\begin{array}{c}\text { Na construção do conhecimento com os estudantes } \\
\text { Nos diálogos de grupo } \\
\text { Auto-organização } \\
\text { Nas relações sociais }\end{array}$ \\
\hline $\begin{array}{l}\text { Plantio de leguminosas } \\
\text { Cobertura morta } \\
\text { Não utilizar agrotóxico } \\
\text { Resgate de sementes crioulas } \\
\text { Consorciamentos de culturas }\end{array}$ & $\begin{array}{c}\text { O trabalho do monitor no CEFFA } \\
\text { As intervenções } \\
\text { A mística } \\
\text { A auto-organização }\end{array}$ \\
\hline $\begin{array}{l}\text { A não utilização de agrotóxicos } \\
\text { Preservação do meio ambiente } \\
\text { Preservação da água }\end{array}$ & $\begin{array}{l}\text { Respeito com as pessoas } \\
\text { Valorização do campesinato } \\
\text { Defender a educação do campo }\end{array}$ \\
\hline $\begin{array}{l}\text { Compostagem } \\
\text { Minhocário } \\
\text { Horta medicinal }\end{array}$ & $\begin{array}{l}\text { Organização dos estudantes } \\
\text { Plano de curso } \\
\text { Formação de mulheres } \\
\text { Manejo sustentável }\end{array}$ \\
\hline
\end{tabular}


Os momentos de estudo seguindo as orientações do plano de cursos numa perspectiva

Uso de homeopatia

Cultivo de hortaliças sem agrotóxico

cuidado com o meio

agroecológica. As relações solidárias respeitando a autonomização e os saberes populares além da utilização da ciência para explicação de fenômenos naturais sociais que possam contribuir na construção do conhecimento agroecológico e da prática agroecológica

Utilização de adubos orgânicos

Minha profissão de educador nos CEFFAS, meu relacionamento com as pessoas e com a natureza, minha família e meu trabalho na roça

Fonte: Dados da pesquisa (2020)

Quando o assunto é prática agroecológica, os educadores, em sua maioria, 57\%, ancoram no viés técnico para delinearem suas práticas agroecológicas, que em sua maioria estão relacionadas ao manejo com a terra e a produção e a utilização de insumos orgânicos na produção, com isso os educadores citam como laboratório tanto a propriedade dos CEFFAS como agricultores ligados aos CEFFAS e movimentos sociais. Por outro lado, $43 \%$ dos educadores ancoram no viés pedagógico para definirem suas práticas agroecológicas, estes materializam a agroecologia no contexto pedagógico dos CEFFAS, são momentos de reflexão com estudantes e agricultores, construídos, na maioria dos casos, a partir dos instrumentos pedagógicos dos CEFFAS.

O educador do CEFFA é o sujeito, não o único, que tem a responsabilidade de mostrar elementos aos estudantes que subsidiem a eficácia da agroecologia como alternativa de vida e produção. Assim, tendo em vista está prerrogativa do educador do CEFFA medimos também quanto estes sentem-se responsáveis pela agroecologia no CEFFA. Para tanto foram dadas 5 opções de escolha aos educadores: nenhuma responsabilidade, pouca responsabilidade, responsabilidade mediana, muita responsabilidade e responsabilidade total. Observamos (conforme o gráfico 1) que nenhum educador escolheu as opções "nenhuma responsabilidade" e "pouca responsabilidade", isso mostra que os educadores se sentem responsáveis com o trabalho da agroecologia, cabendo a estes a tarefa de incentivar a reflexão junto aos estudantes e famílias sobre a temática da agroecologia e que mesmo com todos os desafios existe o espírito de responsabilização por parte destes educadores. 
Gráfico 1: Responsabilização dos educadores respondestes do questionário com a agroecologia (responsabilidade e porcentagem, $n=65$ )

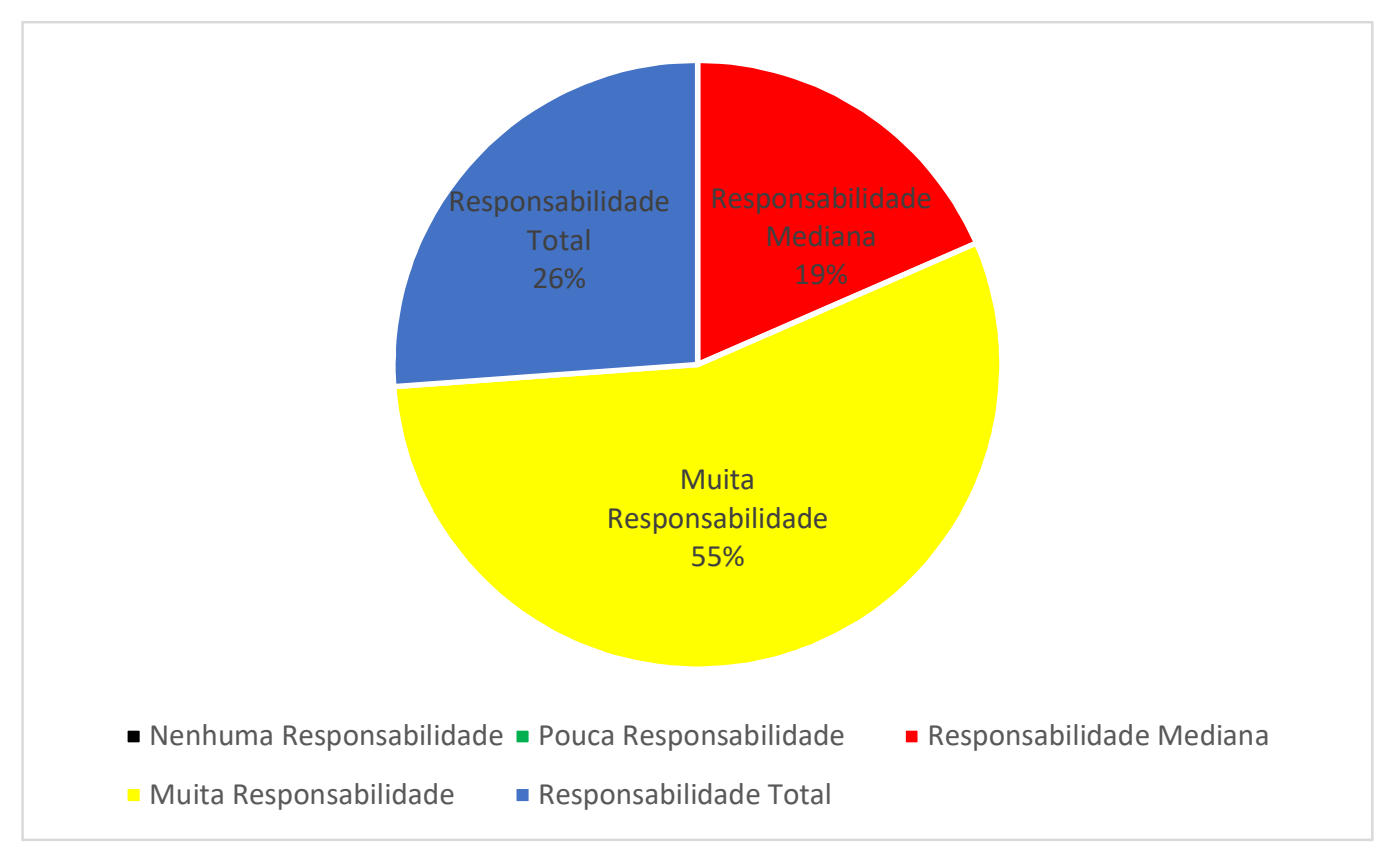

Fonte: Elaborado pelo autor a partir de dados da pesquisa (2020)

Os educadores participantes desta pesquisa carregam consigo um conjunto de lutas que são expressas em palavras de ordem como emancipação e liberdade. Emancipação no sentido de ser protagonista de sua própria história, que sua subsistência não está condicionada aos pacotes tecnológicos do agronegócio; e a liberdade, onde o sujeito é livre para fazer escolhas, livre para plantar o que e quando quiser, livre para vender para quem e onde quiser. São estas expressões que nos levaram a apontar elementos que configuram suas compreensões de agroecologia.

Percebe-se, de acordo com as análises, que a agroecologia não é uma prática exclusiva dos educadores da área técnica, a responsabilização acontece em todas as áreas do conhecimento com relação a agroecologia, até mesmo os educadores recém-chegados nos CEFFAS compreendem a essência e a sua função. Percebemos que ela tem desafios no contexto dos CEFFAS, mas que também vem superando as barreiras políticas, sociais e técnicas de sua difusão, ela tem se afirmado nos CEFFAS como um movimento contraditório ao avanço do capital no território camponês e para tanto, espaços de formação e reflexão estão sendo constantemente sendo promovidos pela Raceffaes. Quanto a 
compreensão destes educadores, esta relaciona-se a determinados referenciais que são construídos de acordo com os contextos acessíveis aos sujeitos.

\section{Considerações finais}

De forma geral a agroecologia foi colocada como uma nova matriz que precisa ser assumida com maior intensidade pelos CEFFAS, espera-se que a agroecologia quando assumida por mais camponeses possa ajudar na formação de pessoas mais comprometidas e protagonistas de seu meio, é preciso mostrar para a sociedade que um jeito de produzir com baixo impacto ambiental e bom retorno financeiro e social é possível. Para os educadores respondentes, a agroecologia é uma forma de viver no campo com dignidade resistindo a opressão do capital, ela é colocada como um movimento, uma ciência e uma prática capaz de promover mudanças no campo e na cidade, para tanto é preciso reinventar e recriar-se, guardando suas essências, tendo em vista o perfil do jovem camponês que é constantemente atraído pelo capital numa perspectiva consumista e financeira. É preciso que a agroecologia se fortifique não só como uma alternativa de enfrentamento ao agronegócio, mas como um movimento de práticas acessíveis aos camponeses, que seja capaz de propor uma qualidade de vida no campo e na cidade, para tanto os CEFFAS têm um papel fundamental na difusão desta ciência.

Sobre a compreensão de agroecologia para estes educadores, pontuamos o lado prescritivo que o contexto exerce na formação de opinião destes educadores. O contexto dos CEFFAS exerce uma força sobre os educadores para militância na agroecologia, assim a compreensão de agroecologia é resultado desta combinação, contexto e militância, que os educadores exercem no cotidiano dos CEFFAS. Este diagnóstico foi possível porque os educadores com menos de 1 ano de trabalho nos CEFFAS e que não conheciam agroecologia antes, conseguiram responder o questionário com elementos relevantes e que refletem a agroecologia dos CEFFAS. Com relação as práticas da agroecologia, encontramos que a maioria dos entrevistados materializam a agroecologia através de elementos de cunho técnico agrário, pontuando ações que remetem a produção sustentável. Isto mostra que a 
agroecologia nos CEFFAS está circulando e se movimentando entre os educadores, tencionando os sujeitos a conhecer e compreender os objetos que os circundam.

Os dados também nos permitem considerar a agroecologia a partir de uma condição pedagógica, ou seja, o termo agroecologia não é apenas uma forma ecológica de manejar a terra, mas também uma proposta horizontalizada de estabelecer relações, pois a mesma pode estar em sintonia com as dinâmicas da natureza e com processos de descentralidade do saber e do ser. Por isso um curso agroecológico e na perspectiva da educação do campo deve dialogar com as diversas instâncias e com as pessoas em seus diversos lugares, também tem como característica a democratização dos espaços coletivos e dos sistemas agroalimentares, isto porque considera que a crise mundial perpassa pela instância ambiental e social.

De modo geral, comprovamos que a agroecologia, assim como a educação do campo, tem vínculo histórico com as lutas dos trabalhadores do campo, por isso é fundamental considerar sua historicidade de contrapor as práticas agrícolas dominantes, que ao longo dos anos sua pauta contrahegemônica foi se ampliando, implicando em desdobramentos práticos e teóricos sobre os processos que orientam as lutas dos camponeses.

\section{Referências}

AYUKAWA, Marcia Lie. Limites e Possibilidades do Ensino de Agroecologia: um estudo de caso sobre o currículo do curso técnico agrícola da Escola Agrotécnica Federal de Rio do Sul/SC. 2005. 164f. Dissertação (Mestrado) Programa de Pós-Graduação em Desenvolvimento Rural, Universidade Federal do Rio Grande do Sul, Porto Alegre, 2005.

CALDART, Roseli Salete; PEREIRA, Isabel Brasil; ALENTEJANO, Paulo; FRIGOTTO, Gaudêncio (Orgs.). Dicionário da Educação do Campo. Rio de Janeiro, São Paulo: Expressão Popular, 2012.

FERNANDES, Bernardo Mançano. MOLINA, Monica Castagna. Análises de Experiências Brasileiras e Latino-Americanas de Educação do Campo. Educação e Sociologia, Campinas, v. 38, n. 140, p.539-544, set. 2017.

FREIRE, Paulo. Pedagogia do oprimido. Rio de Janeiro: Paz e Terra, 1987. 
MENEZES, Rachel Reis. As Escolas Comunitárias Rurais no Município de Jaguaré: um estudo sobre a expansão da pedagogia da alternância no Estado do Espírito Santo/Brasil. 2013. 171 f. Dissertação (Mestrado). Programa de Pós-Graduação do Centro de Educação, Universidade Federal do Espírito Santo, Vitória, 2013.

PIO, Paulo Martins; CARVALHO, Sandra Maria Gadelha de; MENDES, José Ernandis. Práxis e Prática Educativa em Paulo Freire: Reflexões para a Formação e a Docência. In: FARIAS, Maria Isabel et al. Didática e a prática de ensino na relação com a formação de professores. Fortaleza: EdUECE, 2015. pp. 5770-5781.

RIBEIRO, Simone; FERREIRA, Ana Paula; NORONHA, Suely. Educação do Campo e Agroecologia. In: PETERSEN, Paulo; DIAS, Ailton (Orgs.). Construção do Conhecimento Agroecológico: novos papéis, novas identidades. Rio de Janeiro: Articulação Nacional de Agroecologia, 2007. p. 259-269.

SILVA, Lourdes Helena. Concepções \& práticas de alternâncias na educação do campo: dilemas e perspectivas. Nuances: estudos sobre Educação, v. 17, n. 18, p. 180-192, 2010.

SILVA, Lourdes Helena; MIRANDA, Élida Lopes. Educação do Campo e Agroecologia: diálogos em construção. In: Reunião Nacional da ANPEd, 37., 2015, Florianópolis. Reunião. Florianópolis: ANPEd, 2015. p. 1-17.

SIQUEIRA, Leonardo; RIBEIRO, Luiz; ANTUNES-ROCHA, Maria Isabel. Agroecologia como paradigma. Cadernos de Agroecologia, Anais do XI Congresso Brasileiro de Agroecologia, São Cristóvão, Sergipe - v. 15, n. 2, 2020.

SOUSA, Romier da Paixão. Agroecologia e Educação do Campo: desafios da institucionalização no Brasil. Educação e Sociedade, Campinas, v. 38, n. 140, p.631-648, set. 2017.

\section{Sobre o autor}

\section{Leonardo de Miranda Siqueira}

leobsf0640@gmail.com

Professor no Instituto Federal do Espírito Santo - IFES Campus Barra de São Francisco. Doutor em Educação: Conhecimento e Inclusão Social pela Universidade Federal de Minas Gerais, Mestrado em Administração de Empresas, Graduação em Administração de Empresas, Licenciatura e PósGraduação em Matemática. Desenvolve projetos de Ensino, Pesquisa e Extensão com ênfase na Formação de Professores, Educação do Campo e Pedagogia da Alternância.

\section{Maria Isabel Antunes-Rocha}

isabelantunes@fae.ufmg.br 
Graduação em Psicologia pela Universidade Federal de Minas Gerais (1983), Mestrado em Psicologia pela Universidade Federal de Minas Gerais (1995) e Doutorado em Educação pela Universidade Federal de Minas Gerais (2004). Pós-Doutorado pela Universidade Estadual Paulista Júlio de Mesquita Filho/Campus Presidente Prudente. Professora Associada da Faculdade de Educação/Universidade Federal de Minas Gerais. Coordena projeto no âmbito do Programa Pesquisador Mineiro (PPM XI/2017). Coordenadora do Comitê Gestor Institucional de Formação Inicial e Continuada dos Profissionais da Educação Básica (COMFIC/UFMG), do Núcleo de Estudos e Pesquisas em Educação do Campo (NEPCAMPO/FaE-UFMG) e do Grupo de Estudos e Pesquisas em Representações Sociais - GERES). Coordenadora de Projetos de Pesquisa e Extensão nas áreas atingidas por rompimento de barragens. Desenvolve projetos de Ensino, Pesquisa e Extensão com ênfase na Formação e Prática de Educadores, Psicologia Social, Educação do Campo.

\section{Luiz Paulo Ribeiro}

luizribeiro@live.com

Professor Adjunto A no Departamento de Ciências Aplicadas à Educação da Faculdade de Educação da Universidade Federal de Minas Gerais (DECAE FaE - UFMG). Fez sua residência pós-doutoral estudando as correlações entre identidade e representações sociais. Possui doutorado em Educação: Conhecimento e Inclusão Social (FaE-UFMG), mestrado em Promoção da Saúde e Prevenção da Violência pela Faculdade de Medicina da Universidade Federal de Minas Gerais (FM-UFMG) e é graduado em Psicologia pela Pontifícia Universidade Católica de Minas Gerais (PUC Minas). Atualmente coordena as atividades do Grupo de Estudos sobre Representações Sociais (GERES), participa do Colegiado do Curso de Licenciatura em Educação do Campo e coordena as atividades da linha de Pesquisa de Psicologia, Psicanálise e Educação do Programa de Pós-Graduação em Educação: Conhecimento e Inclusão Social da FaE-UFMG. 